\title{
A LITERATURA ENGAJADA EM BELOVED, DE TON1 MORRISON
}

\author{
Tiago Marques Luiz \\ (UFGD) \\ http://orcid.org/0000-0003-4462-3050 \\ Lucilia Teodora Villela de Leitgeb Lourenço \\ (UEMS) \\ https://orcid.org/0000-0001-9063-0994
}

\section{RESUMO}

Este trabalho tem como objetivo apresentar a importância da matéria linguística na literatura, demonstrando resistência em comparação ao nominado inglês padrão. No primeiro momento, são usadas relações específicas do uso do inglês vernáculo negro em detalhes, para indicar a resistência da temática na escrita de Morrison em comparação com o padrão inglês. O corpus escolhido para este artigo é Beloved, de Toni Morrison, no qual o uso do dialeto inglês vernáculo afro-americano estudado por Labov entre outros estudiosos se faz presente. A autora circunscreve sua escrita no movimento pelos direitos civis recomendado por Martin Luther King. Tais características linguísticas que permeiam a escrita de Morrison são peculiares a um seleto grupo de falantes, perpetuado pela segregação estabelecida pela maioria branca e, por estar presente na materialidade literária, demonstra sua natureza cronológica e sociológica de resistência.

PALAVRAS-CHAVE: Movimento dos Direitos Civis. African American Vernacular English. Resistência. Toni Morrison. 


\section{THE ENGAGED LITERATURE IN BELOVED, BY TONI MORRISON}

\section{ABSTRACT}

This paper aims to demonstrate the importance of the linguistic matter in the literature of resistance compared to the Standard English pattern. In the first moment, specific relations of the Black Vernacular English are used in details in order to display the resistance of the theme in Morrison's writing in comparison to the Standard English pattern. The corpus chosen for this article is Beloved, by Toni Morrison, in which the use of African American Vernacular English dialect, studied by Labov among other scholars, is present. The author circumscribes her writing on the civil rights movement recommended by Martin Luther King. Such linguistic characteristics that permeate Morrison's text are peculiar to a select group of speakers, perpetuated by the segregation established by the white majority, and for being present at the literary materiality it demonstrates its chronological and sociological nature of resistance.

KEYWORDS: Civil rights movement; African-American Vernacular English; resistance; Toni Morrison.

\section{Considerações iniciais}

Este é um trabalho de Literatura Comparada que propõe um diálogo com os Estudos da Tradução e com a Linguística. A justificativa para tratar de Toni Morrison no estudo em questão se deve não apenas por ela ter sido premiada pelo Nobel de Literatura em 1993 (o que denota certo grau de importância, dado o fato de ela ser uma escritora das minorias que se tornou cânone) e por receber o prêmio Pulitzer em 1988 com a obra Beloved, mas o que desperta o interesse em estudar a obra Beloved é ela ser um marco linguístico da resistência do público negro perante a hegemonia branca americana.

A obra de Toni Morrison capta a atenção por retratar a questão da escravidão, além de estar marcada pelo uso do dialeto Black English, o que nos permite afirmar que estamos e somos enriquecidos com essa va- 
riedade linguística, que ainda continua viva. E, para corroborar essa reflexão, vamos ao encontro das palavras de Armando Gnisci (2002), que nos diz que Literatura é aquilo que se expressa numa língua distinta, sendo a obra de Morrison uma prova disso.

No campo dos Estudos Literários, mais precisamente no século $\mathrm{XX}$, uma vertente que foi significativa para esse campo foi o advento dos estudos pós-coloniais. Susan Bassnett (1993) é categórica ao dizer que o manuseio da literatura de forma política está atrelado à reconstrução e reafirmação da identidade cultural e nacional em diversas partes do mundo, contribuindo para que as vozes, até então silenciadas, pudessem registrar na escrita literária não apenas uma memória de sofrimento e de subjugação perante um dominante, mas também o registro de uma linguagem que não era aceita nas esferas sociais e acadêmicas, ficando segregada do que era tido como padrão.

A literatura norte-americana serviu de palco para que a chamada AfroAmerican Literature, nicho de representações dos descendentes de seres humanos arrancados de suas origens africanas e escravizados, viesse à tona, dado o passado colonial da América do Norte. Esse contexto favoreceu ao afro-americano sair do anonimato e passar a ser "ser nominado", como demonstra Kimberly Benston:

Para o norte-americano afrodescendente, então, a autocriação e a reformulação de um passado familial fragmentado estão incessantemente interligados: nominação em revisão genealógica inevitavelmente. Toda literatura afro-norte-americana pode ser vista como um vasto poema genealógico que busca restaurar a continuidade das rupturas e descontinuidades impostas pela história da presença negra nos Estados Unidos. (BENSTON, 1984, p. 155, tradução nossa ${ }^{1}$ )

A questão de nominação é apenas uma parte de um todo complexo denominado continuidade restauradora, e esse processo teve respaldo no globo, à medida que a Literatura Comparada estava sendo redefinida. Para Bassnett, tratar da relação entre língua e identidade nacional é um elemento para o estudo da Literatura Comparada, permitindo, dessa forma, que se rompa com o cânone literário e a norma linguística padrão

1 No original: For the Afro-American, then, self-creation and reformation of a fragmented familial past are endlessly interwoven: naming in inevitably genealogical revisionism. All of Afro-American literature may be seen as one vast genealogical poem that attempts to restore continuity to the ruptures and discontinuities imposed by history of black presence in America 
vigente, para dar espaço aos grupos conhecidos como minorias, cujo meio de comunicação era via valorização do dialeto. A comparação de formas e conteúdos em literaturas pós-coloniais e da história dessas mesmas literaturas oferece inúmeras possibilidades (BASSNETT, 1993, p. 76).

No tocante à ruptura com o cânone, David Damrosch (2006) ressalta que ele não foi deixado de lado, mas que está sendo relido e reinterpretado por outras perspectivas, como a do pós-colonialismo, por exemplo. E, para não apenas reler o cânone, Damrosch propõe que leiamos autores provenientes das esferas sociais menos favorecidas, pois esses autores estão dentro da chamada literatura mundial e certamente visam contribuir à formação da fortuna crítica.

Cientes dessas palavras tão contemporâneas e tão caras à nossa historiografia literária, passamos ao próximo tópico desta pesquisa, que diz respeito à obra Beloved e à autora Toni Morrison.

\section{Toni Morrison, Beloved, o movimento pelos direi- tos civis e o Ebonics}

A escritora Toni Morrison, oriunda de Lorain, no estado de Ohio, iniciou sua carreira quando da ebulição do movimento em prol dos direitos civis nos Estados Unidos, o que permitiu que sua produção pungente fosse denominada escrita de resistência, em que ela mostra ao leitor um retrato do corpo negro, elemento que Stuart Hall (2003) trata como importante em suas reflexões; o teórico jamaicano propõe refletirmos como essas culturas "têm usado o corpo como se ele fosse, e muitas vezes foi, o único capital cultural que tínhamos. Temos trabalhado em nós mesmos como em tela de representação" (HALL, 2003, p. 342).

Sobre o motim da tela de representação, temos a personagem Baby Suggs, que num determinado momento da trama, expõe a precariedade que estava sujeita quando era escrava: "aquelas coisas brancas tiraram tudo o que eu tinha ou sonhava" e "quebraram as cordas do meu coração também. Não existe má sorte no mundo sem gente branca" (MORRISON, 2007, p. 127). A escrita de Morrison choca o leitor, lembrando-o dos horrores da escravidão por suas páginas penetrantes, que provocam o nosso interior por meio do dialeto.

No tocante à questão da teoria pós-colonial, a teórica Lois Tyson (2006) sublinha que ela é um amálgama de outras teorizações que servem a nós, escritores e estudiosos da literatura, para refletir sobre a estética literária de origem afro-americana, a partir do olhar do que ela denomina 
ex-colonizado. Essa articulação da produção literária com a crítica pós-colonial é exortada nas palavras de Tyson:

A crítica pós-colonial é particularmente eficaz em ajudar-nos a ver as conexões entre todos os domínios da nossa experiência - o psicológico, o ideológico, o social, o político, o intelectual e o estético - em maneiras que nos mostram como estas categorias são inseparáveis das experiências que temos de nós mesmos e do nosso mundo (TYSON, 2006, p. 417, tradução nossa²).

A partir da fala de Tyson, é possível dizer que a literatura afro-americana, no início da década de 60 , começou a ter voz dentro da produção literária, antes restrita pela hegemonia branca, e que, por ser uma minoria, muitas particularidades da produção literária e da própria História da América do Norte foram deixadas ou relegadas ao segundo plano:

Escolho estes dois exemplos - a resistência dos escravos e o Renascimento do Harlem - porque acho que eles ilustram mais claramente os motivos políticos que estão por trás da exclusão dos afro-americanos da história americana. Uma história conscienciosa de resistência escrava teria explodido o estereótipo racista do escravo contente e estúpido que era grato pela orientação paterna do mestre branco, sem o qual o escravo teria sido uma criança perdida ou um selvagem perigoso. E uma história conscienciosa do gênio literário afro-americano teria detonado o mito da inferioridade afro-americana sobre o qual repousavam tantas políticas e práticas racistas (TYSON, 2006, p. 360, tradução nossa ${ }^{3}$ ).

2 No original: "Postcolonial criticism is particularly effective at helping us see connections among all the domains of our experience-the psychological, ideological, social, political, intellectual, and aesthetic - in ways that show us just how inseparable these categories are in our lived experience of ourselves and our world"

3 No original: I choose these two examples - slave resistance and the Harlem Renaissance - because I think they illustrate most clearly the political motives that lay behind the exclusion of African Americans from American history. A conscientious history of slave resistance would have blasted the racist stereotype of the contented, dim-witted slave who was grateful for the paternal guidance of the white master, without whom the slave would have been either a lost child or a dangerous savage. And a conscientious history of African American literary genius would have blasted the myth of African American inferiority on which so many racist policies and practices rested. 
E, embora a literatura afro-americana nos cative por uma história literária que remonta aos primórdios do século XVIII, por muito tempo, essa riqueza era vista como um desdobramento, mas não como parte da história literária americana. Isso pode ser comprovado por Tyson (2006): os livros didáticos usados para o ensino médio e superior não incluíam essas narrativas na compilação, apenas as obras de escritores brancos do sexo masculino, denotando o caráter hegemônico do cânone literário branco.

Desse ínterim, pode-se afirmar que tanto a crítica pós-colonial como também a crítica afro-americana surgiram para tratar e criticar o caráter político dessa história e historiografia, uma vez que a preocupação reside em trazer as produções artísticas e literárias de um povo, cuja história foi oprimida de forma social, política e, possivelmente, psicológica (TYSON, 2006). Como bem enfatizado pela crítica:

Para muitos americanos negros, isso significa ter um eu cultural em casa e outro eu cultural em espaços públicos dominados por brancos, como o local de trabalho e a escola. E a consciência dupla às vezes envolve falar duas línguas. A cultura negra vivida em casa às vezes inclui o uso do Black Vernacular English (BVE, também chamado de Ebonics ou African American Vernacular English), que preenche todos os critérios gramaticais de uma língua genuína, mas ainda é rejeitado por muitos brancos e alguns negros americanos como precários ou Inglês incorreto, em vez de reconhecido como uma língua em seu próprio direito. Para os escritores negros, a dupla consciência significou ter que decidir se escreveria principalmente para um público negro, um público branco ou ambos. Essa decisão envolve, por sua vez, o tipo de linguagem que o escritor usa (TYSON, 2006, p. 362-363, tradução nossa $)^{4}$.

\footnotetext{
4 No original: For many black Americans this means having one cultural self at home and another cultural self in white-dominated public space, such as the workplace and the school. And double consciousness sometimes involves speaking two languages. Black culture lived at home sometimes includes the use of Black Vernacular English (BVE, also called Ebonics or African American Vernacular English), which fulfills all the grammatical criteria of a genuine language but is still dismissed by many white and some black Americans as substandard or incorrect English rather than recognized as a language in its own right. For black writers, double consciousness has meant having to decide whether to write primarily for a black audience, a white audience, or both. This decision involves, in turn, the kind of language the writer uses.
} 
Os romances de Morrison retratam a complexa questão da identidade dos afrodescendentes, sendo o tema central tratado por ela o modo de vida de um grupo marginalizado do sonho americano: as mulheres negras descendentes dos escravos nos Estados Unidos. Para Kathryn VansSpanckeren (1994), a ficção de Morrison foi tão bem enveredada a ponto de lhe conceder prestígio internacional. Sobre Beloved, a crítica tece o seguinte comentário:

Beloved [A Bem-Amada] (1987) é a história angustiante de uma mulher que mata seus filhos para impedir que vivam como escravos. Emprega técnicas de sonho do realismo mágico ao retratar uma figura misteriosa, Beloved, que volta a viver com a mãe que cortou sua garganta. [...] Morrison sugere que, embora seus romances sejam obras de arte consumadas, contêm sentido político: "Não estou interessada em entregar-me a um exercício privado de minha imaginação... sim, a obra tem que ser política" (VANSPANCKEREN, 1994, p. 117).

Harold Bloom homenageou a escrita morrisoniana ao organizar coletânea de artigos de estudiosos sobre a obra, publicada pela InfoBase Publishing House com o título Toni Morrison's Beloved na série Bloom's Modern Critical Interpretations (2009). O crítico norte-americano começa a sua introdução com a seguinte apreciação de Morrison: a obra da autora tem uma grande importância cultural difícil de ser superestimada, e, no caso de Beloved, em especial, é um romance que o intrigou pelo estilo "notavelmente hábil, barroco em seu esplendor e a autoridade da narrativa está firmemente estabelecida" (BLOOM, 2009, p. 1, tradução nossa $\left.{ }^{5}\right)$. Além da possível semelhança com as obras Enquanto Agonizo (As I Lay Dying), de William Faulkner e Mrs. Dalloway, de Virginia Woolf, Bloom reitera que os romances anteriores de Morrison não eram tão ideologicamente marcados, e que a autora "pôde ter sacrificado grande parte de sua arte no altar de uma política talvez admirável em si mesma, mas não necessariamente a serviço da alta literatura (se alguém quiser conceder que tal entidade ainda exista)" (BLOOM, 2009, p. 2, tradução nossa ${ }^{6}$ ), e acrescenta que a autora deve à Faulkner a inspiração necessária para escrever a obra, algo que esta tem negado firmemente.

5 No original: is remarkably adroit, baroque in its splendor, and the authority of the narrative is firmly established.

6 No original: "may have sacrificed much of her art upon the altar of a politics perhaps admirable in itself, but not necessarily in the service of high literature (if one is willing to grant that such an entity still exists)". 
Nos Estados Unidos, a chamada literatura Afro-American teve como temática a questão diáspora, não apenas para ter o seu espaço no polissistema literário, mas também para mostrar que a escravidão, enquanto mal-estar da sociedade, deixou marcas, as quais não deveriam ser apagadas, e, para isso, a Literatura serve como espaço para representá-las.

Apresentado esse tópico sobre a autora e sua relação com a literatura afro-americana e pós-colonial, passamos agora ao estudo da obra Beloved.

\section{Beloved - um retrato de resistência}

A escrita morrisoniana despertou interesse de teóricos como Homi Bhabha, estudioso dos Estudos Culturais, que, em sua obra $O$ Local da Cultura, dedica o primeiro capítulo à análise de Beloved; no capítulo intitulado "Os Locais da Cultura", Bhabha comenta que a obra retrata "as ambivalências traumáticas de uma história pessoal, psíquica, às disjunções mais amplas da existência política "', e que o assassinato de Beloved é, para ele, uma repetição da "violenta história das mortes das crianças negras durante a escravidão em algumas partes do Sul, menos de uma década depois que o número 124 da Bluestone Road tornou-se mal-assombrado" (BHABHA, 1992, p. 144, tradução nossa ${ }^{8}$ ).

No tocante ao tema e ao enredo da obra, Bhabha faz uma articulação entre a narrativa e a escravidão e os descendentes de seres escravizados, dizendo que Morrison resgata esse passado escravocrata e seus desdobramentos, como o assassinato cruel e a posse e autoposse dos corpos negros, numa ficção "contemporânea da história de uma mulher que é ao mesmo tempo a narrativa de uma memória afetiva, histórica, de uma esfera pública emergente, tanto de homens quanto de mulheres" (BHABHA, 1998, p. 25).

Em O Bazar Global e o Clube dos Cavalheiros Ingleses (2011), Homi Bhabha dedica um capítulo completo a Toni Morrison, intitulado "Ágora e Aura". A rememoração da história global da escravidão no final de Beloved é comentada por Homi Bhaba a partir das palavras do epílogo de Toni Morrison em Beloved: "Não se trata de uma história para passar adiante" (MORRISON, 1987, p. 275). Para Bhabha, "ela é entoada conforme marca com fogo, mais profunda e densamente, na carne "daquela 7 No original: "the traumatic ambivalences of a personal, psychic history to the wider disjunctions of political existence"

8 No original: "violent history of black infant deaths, during slavery, in many parts of the South, less than a decade after the haunting of 124 Bluestone Road." 
memória que espouca em um momento de perigo" (BHABHA, 2011, p. 129).

Ainda sobre Beloved, Bhabha retoma a temática no capítulo intitulado "O entrelugar das culturas", em que ele afirma que a obra é manifesta de ritmo e improvisação, e que serve não apenas para impactar, mas para fazer com que o leitor veja em seus capítulos "a cura da história, uma comunidade apaziguada na afirmação de um nome" (BHABHA, 2011, p. 92). E conclui:

Quem é Beloved? Agora compreendemos: Ela é a filha que volta para Sethe, de forma que sua mente não será mais sem-teto. Quem é Beloved? Agora podemos dizer: Ela é a irmã que volta para Denver e traz a esperança da volta de seu pai, o fugitivo que morreu na fuga. Quem é Beloved? Agora sabemos: Ela é filha feita de amor mórbido, que volta para amar e odiar e se libertar. Suas palavras estão quebradas, como as pessoas linchadas de pescoços quebrados; desincorporadas, como as crianças mortas que perderam as rédeas. Mas não há nenhum engano quanto ao que as palavras vivas dizem, quando se levantam dos mortos, apesar de sua sintaxe perdida e de sua presença fragmentada (BHABHA, 2011, p. 92).

Para Bloom (2009), os eventos descritos em Beloved "podem estar além da capacidade da própria representação literária, que é um enigma que prejudicou qualquer tentativa de retratar a matança nazista dos judeus europeus" (BLOOM, 2009, p. 2, tradução nossa9), conforme a seguinte passagem do texto:

He is staring at the quilt but he is thinking about her wroughtiron back; the delicious mouth still puffy at the corner from Ella's fist. The mean black eyes. The wet dress steaming before the fire. Her tenderness about his neck jewelry - its three wands, like attentive baby rattlers, curving two feet into the air. How she never mentioned or looked at it, so he did not have to feel the shame of being collared like a beast. Only this woman Sethe could have left him his manhood like that. He wants to put his story next to hers. "Sethe," he says, "me and you, we got more yesterday than anybody. We need some kind of tomorrow." He leans over and takes her hand. With the other he touches her face. "You your best thing Sethe. You are." His holding fingers are holding hers. "Me? Me?" (MORRISON, 1987, p. 273).

9 No original: may be beyond the capacity of literary representation itself, which is an enigma that has crippled every attempt to portray the Nazi slaughter of European Jewry. 
Tanto Alice Walker, autora de A Cor Púrpura (1982), quanto Toni Morrison ressaltam o meio de comunicação intraétnico, o African American Vernacular English, Ebonics, Black English ou Spoken Soul como uma ferramenta a fim de valorizar a cultura. O romance morrisoniano Beloved inicia em Cincinatti, estado de Ohio, onde Sethe, como escrava fugitiva, vive com a filha Denver, de dezoito anos. A sogra de Sethe, Baby Suggs, falece pouco tempo depois.

Em relação aos seus romances, pelos quais é mais conhecida, Morrison tece uma narrativa de forma peculiar, por meio de técnicas de fluxo de consciência, com uma gama de perspectivas e uma cronologia não linear, revelando e retratando, por meio de seus personagens, as lutas individuais e coletivas dos afro-americanos em uma sociedade hegemônica branca. E um elemento que merece destaque é a marca da oralidade por meio do dialeto acima mencionado, o que ela comprova na seguinte citação do texto "Rootedness: The Ancestor as Foundation" (1984):

Há coisas que eu tento incorporar na minha ficção que são direta e deliberadamente relacionadas àquilo que considero como as principais características da arte negra, onde quer que ela esteja. Uma delas é a capacidade de ser literatura oral e escrita ao mesmo tempo: combinar esses dois aspectos de forma que as histórias possam ser lidas silenciosamente, é claro, mas também ouvidas (MORRISON, 1984, p. 59, tradução nossa $\left.{ }^{10}\right)$.

Para ela, o romance Beloved serviu como um curativo para uma dor enraizada historicamente: a escravização dos africanos, e as palavras que nele foram escritas corporificam um marcador histórico para lembrar-nos de que essa mazela não ocorra novamente. E como efeito de verossimilhança, Beloved retrata a história de Margareth Garner, segundo William L. Andrews e Nellie Y. Mckay (1999): era uma escrava fugitiva de Kentucky, que foi perseguida até Ohio e capturada pelas autoridades escravocratas. Para evitar que sua família tivesse o mesmo destino, ela matou um dos três filhos, e se não tivesse sido impedida, teria matado os outros dois. Ao ter contato com essa história, Morrison "ficou impressionada

10 No original: "There are things that I try to incorporate into my fiction that are directly and deliberately related to what I regard as the major characteristics of Black art, wherever it is. One of which is the ability to be both print and oral literature: to combine those two aspects so that the stories can be read in silence, of course, but one should be able to hear them as well" 
com a enormidade do feito da mãe e arquivou a informação por quase uma década antes de escrever sobre ela. Essa notícia foi o núcleo do qual Beloved emergiu no final dos anos 80" (ANDREWS; MCKAY, 1999, p. 6 , tradução nossa $\left.{ }^{11}\right)$.

Morrison realizou pesquisas para tornar o enredo de Beloved profundo, como por exemplo, os instrumentos de tortura de escravo, porém, apesar de ter tido contato com a história de Garner, a escritora opta por uma maior liberdade para com a narrativa de seus personagens (ANDREWS; MCKAY, 1999).

No início da trama, os filhos de Sethe, Haward e Buglar, fogem de casa atormentados pela presença de um fantasma malévolo que assombra a casa da rua Bluestone Road. Denver se afeiçoa ao fantasma que um dia surge encarnado para viver com eles. Juntamente com Paul D, Sethe e o marido Halle haviam sido escravos em propriedade rural chamada Sweet Home, de propriedade de Mr. Garner.

O texto divide-se em capítulos de ordem inversa, com solilóquios e flashbacks dos acontecimentos ocorridos há duas décadas nessa propriedade, no estado de Kentucky, alternando-se com o presente da narrativa, em Ohio. O texto requer diversas leituras, ao estilo de Virginia Woolf e James Joyce. As cenas em vai e vem, entre o presente e o passado, compõem uma Ilíada diaspórica da africanidade, com relatos e descrições de sofrimentos impostos aos escravos fugitivos como estupros e assassinatos por insubordinação.

Os Garners estabelecem uma relação mais liberal com seus escravos em relação a outros proprietários de escravos. Na fazenda deles, Sethe chegou quando criança e, aos treze anos de idade, já havia homens que a cortejavam: Sixo, Paul A, Paul D, Paul F e Halle. Ela desposa Halle, personagem generoso, que trabalhou nos finais de semana para comprar a liberdade da mãe, Baby Suggs.

Após a morte de Mr. Garner, o sobrinho assume o controle da fazenda e é chamado pelos escravos de 'professor de escola', em razão de sua rigidez. As atitudes do professor fazem com que a opressão se torne insustentável para os escravos e esses tomam a decisão de fugir. Os escravos Paul D e Sixo fogem, porém são capturados ao iniciarem a fuga e

11 No original: was struck by the enormity of the mother's deed and filed the information away for almost a decade before acting on it. That news item was the kernel from which Beloved emerged in the late 1980s 
castigados severamente. Sethe é vitimizada pelos sobrinhos do 'professor de escola' que tiram à força o leite materno de seu bebê. $\mathrm{O}$ marido de Sethe, Halle, presencia a cena e enlouquece. Paul D é forçado a permanecer com o freio na boca, instrumento de tortura muito comum entre os proprietários de escravos, e Sixo é morto.

Ao descobrirem que Sethe relatou para Mrs. Garner a violência cometida pelos sobrinhos do professor, a escrava é submetida a uma sessão de chicotadas e suas costas ficam profundamente marcadas com uma cicatriz imensa, em formato de árvore. Mesmo assim, ela foge e, no percurso, dá à luz a uma menina, com a ajuda de uma moça branca com a qual se depara em meio a sua fuga, Amy Denver. Sethe vai para Cincinatti encontrar a sogra, uma pastora evangélica que atende a uma comunidade negra com reuniões em uma mata.

Um mês após a chegada de Sethe à casa de Baby Suggs, o 'professor de escola' consegue descobri-la ali e chega para levá-la de volta à fazenda. Para evitar que o bebê de dois anos sofresse os horrores da escravidão quando se tornasse adulta, Sethe serra o pescoço da filha em um ato extremo. Ela planejava matar os outros filhos também, mas é impedida por aqueles que estavam na casa junto com ela. $\mathrm{O}$ túmulo de sua filha recebe uma lápide gravada com "Beloved", que significa "bem-amada". Sethe é presa e condenada, posteriormente é libertada por abolicionistas, e a família continua vivendo em isolamento.

Paul D caminha durante sete anos para chegar à casa de Sethe, quando passa a morar com sua antiga amiga. Logo depois de sua chegada, uma moça misteriosa aparece na casa de Sethe e ali permanece. Ao longo do tempo, essa personagem parece ser a própria Beloved. Ela seduz Paul $\mathrm{D}$, engravida e depois desaparece. Sethe se interessa apenas por Beloved, perde o emprego e adoece. A filha Denver sai em busca de trabalho, conhece um rapaz e reconstitui a sua vida.

Na narrativa, Morrison emprega técnicas do realismo mágico ao retratar a jovem Beloved. A estética da obra é caracterizada pelo uso do dialeto Black English ou Ebonics, como mencionado anteriormente, uma subversão à norma padrão que mescla a norma padrão e o dialeto. As experiências vividas por seus personagens são tão grotescas e vulneráveis que só a faculdade de poderem lembrar era algo vergonhoso e perigoso, mas nada se compara ao fato de Sethe ser assombrada pela lembrança de ter matado seu bebê. Beloved serviu como uma forma de devolver a dignidade a um povo vitimado pela História. 


\section{O Ebonics em Beloved - o contexto do movimento pelos direitos civis}

A obra de Morrison é marcada pelo uso frequente do dialeto, contudo, faz-se necessário contextualizar o movimento dos direitos civis, que foi um momento crucial para que a obra surgisse.

A Inglaterra teve domínio de treze colônias, cada uma com um propósito diferente. Nos estados sulistas, a agricultura dependia unicamente da mão-de-obra escrava, ao passo que os estados do Norte já eram industrializados, necessitando pouco da mão-de-obra, e, dessa maneira, havia muitas divergências de caráter político e econômico, que vieram a se acentuar após a independência dos Estados Unidos em 1776.

Tais divergências resultaram na Guerra Civil, empenhada pelos estados separatistas da Carolina do Sul, Carolina do Norte, Flórida, Alabama, Texas e Geórgia. Os estados do norte venceram a guerra, e a abolição dos escravos deu-se em 1863, assinada pelo Presidente Abraham Lincoln, porém, a esfera social, jurídica e política dos afro-americanos não teve progresso, e somente um século depois, mais precisamente em 1950, que a comunidade afro-americana foi contemplada pelo levante dos direitos civis a seu favor, movimento esse que foi liderado pelo teólogo da igreja Batista, Dr. Martin Luther King Jr. A atuação de King em prol da causa foi tão extraordinária a ponto de receber o prêmio Nobel da Paz em 1955.

Em 1968, quando organizou uma manifestação pacifista em Washington D.C., atraiu duzentas e cinquenta mil pessoas às ruas, com seu famoso manifesto I have a dream. Considerando que o racismo norte-americano era mais acirrado no sul dos Estados Unidos, logo após, Dr. King foi assassinado em Memphis, estado do Tennessee, em 4 de abril de 1968, aos 39 anos de idade, abatido por um tiro de fuzil. Após sua luta incansável pelo fim do apartheid (Manifesto I have a dream) e assassinato em 4 de abril de 1968, os povos afrodescendentes começaram a ocupar os mesmos espaços que os brancos, porém, no âmbito educacional, o sistema linguístico adotado ainda era a norma padrão.

No dia 21 de agosto de 2013, foi celebrado o cinquentenário do movimento pelos direitos civis acima referidos, porém, a data ainda não demonstrou total aplicabilidade; o uso do dialeto vigora como elemento de exclusão social, principalmente no espaço escolar, que é onde se inicia a caminhada pela aprendizagem, ainda em vigência com a "língua estrangeira" padrão a ser ensinada aos afrodescendentes. E, como bem 
enfatizado por Lucilia Lourenço (2014), mesmo havendo um salto de inclusão, ainda "não há perspectivas de mudanças que instrumentalizem professores no dialeto para que possam ensinar a norma padrão como novo código linguístico" (LOURENÇO, 2014, p. 64).

O termo inglês Ebonics foi proposto em 1972 pelo psicólogo Robert L. Williams, conhecido pelo teste Black Intelligence Test of Cultural Homogeneity, que era elaborado para proporcionar aos negros a mesma oportunidade nos testes comuns, os quais eram voltados ao vocabulário da hegemonia branca, contudo, esse teste seguia uma orientação inversa: em vez de facilitar e permitir o acesso da criança negra ao ensino acabava contribuindo para que fossem elevados os índices incorretos de inteligência de crianças negras.

Outro termo que também é conhecido dos falantes afro é o dialeto chamado Spoken Soul, cunhado por Claude Brown em 1968 (cf. RICKFORD, 2000, p. 3). Na literatura morrisoniana, essa variante dialetal matiza o texto. A obra, como foi mencionado anteriormente, se inspira num fato verídico: a história de Margareth Garner, situada na metade do século XIX, em que culminava a publicação da ordem judicial conhecida como Fugitive Slave Act de 1850, que recompensava os captores pela captura dos escravos.

O mérito resistencialista de Morrison se dá pela intertextualidade com a história de Garner, em que a autora ficcionaliza essa personagem e sua trajetória por meio de Sethe, que toma a mesma atitude radical para evitar que a sua criança esteja sujeita aos sofrimentos da escravatura, o que nos permite denotar que o texto literário funciona como um resgate da memória de um passado que não pode ser esquecido.

Além das questões literárias, Bhabha traz à tona a questão dialetal inserida no sistema educacional norte-americano. É sabido que as crianças têm uma educação pelo dialeto, tanto em seus domicílios como na comunidade em que estão inseridas, porém, como o sistema educacional norte-americano exige o uso da norma culta inglesa, que é desconhecida dessas crianças por não ser parte do seu universo linguístico, consequentemente, no momento em que frequentam o espaço escolar, sentem um complexo processo de se adaptar e de incluir esse sistema padrão.

Por essa razão que, para nós, é falha do sistema educacional não reconhecer a diversidade linguística no âmbito da comunicação, as crianças são alocadas em turmas de educação especial, tornando-as semianal- 
fabetas e, consequentemente, impossibilitadas de adentrar no mercado de trabalho, sendo o crime a única alternativa. Sobre o desconhecimento do dialeto negro por parte dos professores que aplicam os testes de inteligência usados pelas escolas norte-americanas para avaliar seus alunos, Homi Bhabha se manifesta:

As descrições e as definições sociolingüísticas de vernaculização certamente têm importante contribuição pedagógica a dar. Quem poderá negar que um conhecimento da estrutura profunda do inglês dos negros não iria auxiliar os professores em suas tentativas de avaliar o desempenho e de extrair os melhores resultados daqueles que estão em desvantagem do ponto de vista educacional? (BHABHA, 2011, p. 64-65).

De tudo o que foi exposto até o presente momento, Beloved não é apenas um romance, um bestseller, é um manifesto político e social fundamental para a história e condição dos afrodescendentes.

William Labov (1972/2008) foi um pesquisador reconhecido no campo da sociolinguística variacionista na década de 1960/1970, tornando-se militante contra as políticas de discriminação e de exclusão social. Um de seus famosos manifestos é o artigo de 1966, intitulado "A lógica do inglês não padrão", em que defende o inglês proveniente da comunidade afro-americana, afirmando que é um sistema linguístico com normas próprias, e que são coerentemente seguidas pelos seus falantes.

O African American Vernacular English (AAVE), também chamado Black English,Black Vernacular ou Black English Vernacular (BEV), Ebo ou Jive ou Spoken Soul constitui uma variedade linguística considerada dialeto, socioleto e etnoleto da Língua Inglesa Norte-Americana. Os estudos de William Labov têm inspirado aqueles que reconhecem na prática da língua o mais importante elemento da cultura e da vida em sociedade. A variedade é falada por muitos afrodescendentes nos Estados Unidos da América e entre minorias étnicas afrodescendentes em várias partes do mundo.

Nesse sentido, apresentamos uma pequena amostragem das construções gramaticais e de sintaxe da pouco conhecida variedade linguística Ebonics, desde a década de 1970, considerada uma língua, com a finalidade de facilitar a identificação do dialeto. A seguir serão apresentados breves exemplos de suas características retiradas dos estudos de J. L.Dillard, J. A. Harrison, em Perspectives on Black English, 1975 (p.143-140) e de J.R. Rickford e R. J Rickford, pai e filho, respectivamente (2000, p. 109-128): 
- Omissão da cópula be: He quick in everything.

- Inclusão do be para aspecto habitual ou tempo futuro: they be slow all the time. The boy be here soon.

- Inversão da sintaxe: Can't nobody read minds.

- Repetição do pronome substantivo sempre que a referência for terceira pessoa, como duplo sujeito: Miss, Nelle, she pointed../. Shelby he told us...

- Aspecto inclusivo do done: You done gone and bought your father a hat?

- Múltipla negação: There ain't nothing the matter.

- Uso do ain't: como forma negativa de is-are-am e excluindo os auxiliares have e has: He ain't a good man.

-Flexão equivocada do verbo to be: I is

-Flexão equivocada de verbo irregular: She bringed/brung de termartusses (tomatoes)

- Uso do negativo de has: Don't she have a house down there?

- Forma negativa com be: She don't be listening.

- Uso do singular is em lugar do plural are: My children is men.

- Marco de pluralidade associativa com dem: John and dem- significando John and his friends/John e seus amigos.

- Uso de dem como pronome demonstrativo. Dem boys is here como pronome demonstrativo/ou them books/aqueles livros.

- Uso de them como artigo indefinido: them man: um homem.

- Uso de it is ou it's ao invés de there is ou there are.

- Uso do plural equivocado: Many's the time.

- Ausência da flexão de terceira pessoa do singular do presente do indicativo: It seem like, when I be driving, it seem like every corner I drive around. Ou She have a sister.

- Ausência da flexão com do: He do/ He don't - She have/ She haven't.

- Ausência de possessive 's: John came over to that girl house.

- Uso impróprio do verbo to need: She needing.

- Ausência de verbo auxiliary: what he do that for?

- Impossibilidade de excluir infinitivo be após: can, to, may, must, shall, would, will: You can be sitting up in class and next thing you know, you out of it.

- Uso de been seguido de gerúndio: I been playing cards since I was four. 
- Uso de BEEN - marcado: I BEEN finished!

- Uso do done como característica enfática como mesmo significado de: I've already I done had enough!

- Done como futuro perfeito: I'll be done bought my own CD waiting on him to buy me one.

- Done com be como futuro: After a few weeks the Puerto Ricans be done took [ = will have taken ] over.

- Done como condicional: If she [ = a dog] wasn't spayed, she'd be done [would have got pregnant because she gets out].

- Done como tempo habitual: The children be done ate [ = have usually eaten] by the time I get there.

- Finna, fidna ou fitna - usado para futuros imediatos, é derivado de fixing: - He is fixing to go - evolui linguisticamente para finna: "This thang finna get turned out, so y' all better get in yo'lit car an'...go home."

- Impossibilidade de exclusão de am. I am é frequentemente contraído: I'm.

- Modais duplos ou triplos: He might could do the work. She may can do the work. They should oughta go. They might should aughta do it.

- Interrogativo oposto ao inglês padrão, realizado sem inversão, apenas com aumento de entonação: This is a microphone, too?

- Ordem das palavras invertidas, omissão de if ou whether : I asked him could he come [if he could come] with me.

- Verbalização equivocada a partir de substantivo: I birthed them.

- Omissão de auxiliar have or had, antes de been: I been good.

- Substituição de I por me.

- Uso da expressão plum, como ênfase. He plum went mad.

- Inversão de ordem de palavras, omissão de if ou whether: I asked her she could come with me.

- Uso de interjeições dorggone: I be dorggone if.

- Uso de interjeição doggone: I be doggone she leave me.

- Prefixação de a, antes das formas verbais: Iwould a do.

- Supressão da primeira sílaba não marcada: because /kauz/expect/ spek/about/bawt/.

- Simplificação da consoante. Na oralidade destacamos: grand/gra$\mathrm{em} / \mathrm{moved} / \mathrm{muv} / \mathrm{just} / \mathrm{jis}$.

- Simplificação de ditongos: My/mah/time/tahm/I/ah /rice/rahce.

- Caso possessivo: formado por acréscimo de s, es ou z. Masters gun, Missuses dress. 
- Comparative duplo e superlative, usados como no inglês elizabetano são muito frequentes: de bes's 'bestest', de mos'deepist water I ever seed.

Acrescenta-se em adição, exemplos de cinco tipos de tempos verbais presentes no Ebonics e seu equivalente em norma padrão de língua inglesa:

1. He runnin. (He is running.)

2. He be runnin. (He is usually running, or $\mathrm{He}$ will/would be running.)

3. He be steady runnin. (He is usually running in an intensive, sustained manner, or He will/would be running in an intensive, sustained manner.)

4. He BEEN runnin. (He has been running - at some earlier point but probably not now.)

5. He BEEN runnin. (He has been runinng for a long time, and still is.)

As características descritas não esgotam o conteúdo da bibliografia citada acima, no entanto, servem para exposição das peculiaridades do Black English com consequente percepção da linguagem oral praticada nos Estados Unidos como meio de comunicação intraétnica, fato que retrata a impossibilidade da compreensão do dialeto pela população branca devido às inúmeras mudanças linguísticas em relação à norma padrão.

\section{Considerações Finais}

O estudo do romance Beloved, de autoria de Toni Morrison, relata as fugas que escravas grávidas empreendiam ao cruzar as fronteiras para outros estados. No romance Beloved, a mãe mata a filha a fim de livrá-la do suplício da escravidão. O texto nos conduz ao surreal, ao introduzir no texto literário a figura sobrenatural da jovem morta quando bebê que retorna de outra dimensão para executar sua vingança.,

A crueldade dos senhores de escravos, o racismo, a violência e a miséria são descritos por Morrison com o uso do dialeto African American Vernacular, que conduz o leitor a um universo da desigualdade e do sofrimento perpétuo.

O romance Beloved direciona o leitor a reflexões sobre a questão racial, a pobreza, o poder das pessoas influentes, a maldade dos caçadores de escravos. Considerado um dos melhores romances sobre a questão étnica, Beloved é também um texto sobre amor e ódio. 


\section{REFERÊNCIAS BIBLIOGRÁFICAS}

ANDREWS, William L.; MCKAY, Nellie Y. Toni Morrison's Beloved: A Casebook. New York/Oxford: Oxford University Press, 1999.

BASSNETT, Susan. Comparative Literature: A critical introduction. Oxford: Blackwell, 1993.

BENSTON, Kimberley. I yam what I am: the topos of (un)naming in Afro-American Literature. In: GATES JR., Henry Louis (Ed). Black Literature and Literary Theory. New York and London: Methen, 1984. p. 151-175.

BHABHA, Homi K. The world and the home. Social Text, n. 31/32, Third World and Post -Colonial Issues, 1992. p. 141-153.

. O Bazar Global e o Clube dos Cavalheiros Ingleses: textos seletos. Organização de Eduardo Faria Coutinho, Introdução por Rita Terezinha Schmidt. Tradução de Teresa Dias Carneiro. Rio de Janeiro: Editora Rocco, 2011.

O Local da Cultura Tradução de Myriam Ávila, Eliana Lourenço de Lima Reis e Gláucia Renate Gonçalves. Belo Horizonte: Editora da UFMG, 1998.

BLOOM, Harold. Toni Morrison's Beloved. Edited and with an introduction by Harold Bloom. Bloom's Modern Critical Interpretations. New York: Infobase Publishing, 2009.

DAMROSCH. David. World Literature in a Postcanonical, Hypercanonical Age. In: SAUSSY, Haun (Ed.). Comparative literature in an Age of Globalization. Baltimore: The Johns Hopkins University Press, 2006. p. 43-53.

GNISCI, Armando. Introducción a La Literatura Comparada. Barcelona: Editorial Crítica, 2002.

HALL, Stuart. Da Diáspora: identidades e mediações culturais. Tradução: Adelaine L. Guardia Resende. Belo Horizonte: Editora UFMG, 2003.

LOURENÇO, Lucilia Teodora Villela de Leitgeb. Traduzindo o intraduzível: estudo de duas traduções em língua portuguesa de Beloved, de Toni Morrison. 2014. 108f. Tese (Doutorado em Letras). Instituto de Letras, Universidade Federal do Rio Grande do Sul, Porto Alegre, 2014.

MORRISON, Toni. Rootedness: The Ancestor as Foundation. 1984. In: DENARD, Carolyn C. (Org.). What Moves at the Margin: Selected Non-Fiction. Jackson: University Press of Mississippi, 2008. p. 56-64.

Beloved. New York: Plume, 1987. 
RICKFORD, John. Spoken Soul. New York, Chichester, Weinheim, Brisbane, Singapore, Toronto: John Wiley \& Sons, Inc. 2000.

TYSON, Lois. Critical Theory Today: a user-friendly guide. $2^{\text {nd }}$ edition. New York and London: Routledge, 2006.

VANSPANCKEREN, Kathryn. Perfil da Literatura Norte-Americana. Edição revisada. Tradução de Márcia Biato. USA: Departamento de Estado dos Estados Unidos da América, 1994.

Recebido em: 30/04/2019

Aceito em: 30/09/2019 